Research Article

\title{
Experimental Study on the Shear Performance of Shallow Hinge Joints for Prefabricated Hollow Slab Bridges
}

\author{
Hanbin Yi $\mathbb{D}^{1,2}{ }^{1,2}$ Chuanxi Li, ${ }^{1}$ and Li Dai ${ }^{2}$ \\ ${ }^{1}$ Bridge Engineering Department, Changsha University of Science and Technology, Changsha 410076, China \\ ${ }^{2}$ Research and Development Center on Technologies and Equipment of Long-span Bridge Construction, Ministry of Transport, \\ Nanchang 330100, China \\ Correspondence should be addressed to Hanbin Yi; 272864631@qq.com
}

Received 14 March 2018; Accepted 19 July 2018; Published 27 August 2018

Academic Editor: Ahmed Mebarki

Copyright (c) 2018 Hanbin Yi et al. This is an open access article distributed under the Creative Commons Attribution License, which permits unrestricted use, distribution, and reproduction in any medium, provided the original work is properly cited.

\begin{abstract}
To investigate whether shallow hinge joint fracture was caused by shear stress or flexural stress, during the demolition and reconstruction of Xiaojiang River bridge, two original girders were collected and shipped to the lab, and the shallow hinge joint between the two girders was rebuilt. Tests were performed to investigate the cracking load, failure mode, and force transmission performance of the hollow slab girder and shallow hinge joint under vehicle load. The test result shows that under eccentric load, when the load increases to $365 \mathrm{kN}$, the midspan bottom slab of the testing girder starts to fracture; as the load increases to $560 \mathrm{kN}$, the roof slab of the testing girder starts to fracture; the hinge joint has a maximum horizontal opening of $0.153 \mathrm{~mm}$ and vertical relative displacement of $0.201 \mathrm{~mm}$; during the entire test loading process, the shallow hinge joint structure does not develop fracture and shear failure; and the shallow hinge structure demonstrates excellent shear stress transmission performance. In addition, based on hinge slab theory, the hinge joint internal force under vehicle load was calculated. Based on ACI 318-05 specification, CAN/CSA-S6-00, and JTG D61-2005, the hinge joint shear bearing capacity was calculated. Hinge joint stress resistances calculated from the three specifications all exceed the internal force. Among them, the calculation results from ACI 318-05 and CAN/CSA-S6-00 are similar, while the result from JTG D61-2005 specification significantly exceeds the internal force, which is mainly because the designed concrete direct shear strength $f_{\mathrm{vd}}$ in the Chinese specification does not consider factors such as bonding surface coarseness, concrete pouring sequence, and material properties. Theoretical calculations and tests show that the actual failure mode of the shallow hinge joint in prefabricated hollow slab girder bridges is not caused by shear stress.
\end{abstract}

\section{Introduction}

Prefabricated hollow slab bridges with a shallow hinge structure were first used in the 1970s [1]. Since the 1990s, the shallow hinge joint structure has gradually been abandoned and replaced by the deep hinge joint structure [2]. According to statistical analyses, medium to small highway bridges with spans under $20 \mathrm{~m}$ in China mostly have a prefabricated hollow slab structure [3]. After decades of use, a large number of prefabricated hollow slab bridges, especially those with shallow hinge joint hollow slab, have developed hinge joint fracture failure due to the innate deficiency of hinge joint structure design and construction as well as later stage factors such as vehicle overloading and environment erosion, eventually resulting in the problem of "stress on a single slab."

Hinge joint failure has a severe impact on the safety of prefabricated hollow slab bridges and the development of this type of bridge. Therefore, researchers in China have conducted extensive research on hinge joint strain and failure mechanisms. Jianshu et al. [4] designed a test for hinge joint shear performance and proposed a formula to calculate the hinge joint shear strength and bearing capability. Yongfeng [5], Tiecheng et al. [6], and Xianxi et al. [7] 
conducted model and experimental studies on prefabricated hollow slabs with various forms of hinge joint connections and hinge joint reinforcements and presented the following conclusions: (1) As the hinge joint height increases, the horizontal connection performance of adjacent slabs improves accordingly. (2) Fatigue load is a major factor for shallow hinge joint failure. (3) Compared with the hinge joint without rebar, adding cross rebar and door rebar at the hinge joint improves the load transmission capability of the hinge joint. Qu et al. [8] designed and produced a full-scale model of a hollow slab bridge with an $8 \mathrm{~m}$ span and a deep hinge joint structure, and the following test results were obtained: (1) When the load increases to $70 \mathrm{kN}$, i.e., 1.0 times the designed vehicle load (highway-grade I), the bonding surface between the hinge joint and hollow slab fractures. (2) When the load increases to $140 \mathrm{kN}$ (2.0 times the designed vehicle load), the fracture penetrates to the top of the hinge joint to form a penetrated fracture; additionally, the hinge joint is in the flexural failure mode.

Studies on the stress performance and failure mode of shallow hinge joint structures under vehicle load are scarce in China. Additionally, the mechanism of hinge joint failure remains unclear. Although hollow slab girder bridges with shallow hinge joints are no longer being designed, there is still a large number of this type of hollow slab bridge in operation. Therefore, whether the bearing capability of the shallow hinge joint structure is "inferior" is worth investigating. Additionally, proper use of this type of structure, reinforcement, and rebuilding has significant engineering value. Therefore, in this paper, based on the related experimental study of similar hollow slabs [9-13], two prestressed concrete hollow slabs with a $20 \mathrm{~m}$ span (with shallow hinge joint structure) are used to investigate the stress mechanisms of the shallow hinge joint structure under the vehicle load.

\section{Prototype Test Design}

Six original girders collected from a demolished and reconstructed prefabricated hollow slab bridge from the Changzhang highway reconstruction and expansion project were sent to the lab, and two slabs were selected to create the test model.

The parameters of each hollow slab are as follows: precast width, $155 \mathrm{~cm}$; height, $90 \mathrm{~cm}$; top/bottom slab thickness, $10 \mathrm{~cm}$; and web thickness, $11 \mathrm{~cm}$. Each slab had 15 ASTM A416-90a 270 grade (diameter of 0.6 inch) steel strands (Figure 1), and the hollow slab was based on no. 40 gravel concrete.

The dimensions of the shallow hinge joint are shown in Figure 2(a). Connection rebar N1 is buried in the hollow slab with $10 \mathrm{~cm}$ spacing along the direction vertical to the bridge. The detailed structure is shown in Figure 2(b). There are two types of hinge joint rebar structures, scissor rebar N2 and longitudinal rebar N3 with $10 \mathrm{~cm}$ spacing along the direction vertical to the bridge. Details are shown in Figure 2(c).

As the hinge joint was completely damaged when the hollow slab was sent from the field to the lab, before test, the original hinge joint concrete was removed completely; part of bridge surface pavement layer was removed; and
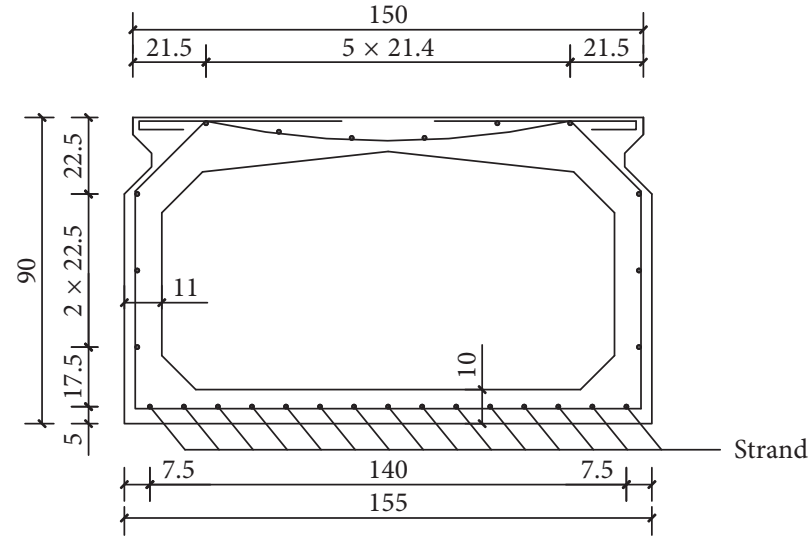

FIGURE 1: Wide prefabricated concrete hollow slab midspan section $(\mathrm{cm})$.

then, the blocks were hoisted to the support (one end of the test girder support was slab rubber support, and the other end was Teflon slide plate rubber support), as shown in Figure 3. After the rebar was added to the hinge joint, C40 grade concrete was poured onto the hinge joint and the bridge surface pavement layer. The concrete bridge surface pavement layer was $10 \mathrm{~cm}$ thick. A layer of $\phi 8$ plain round rebars was deployed along the girder longitudinal direction with $10 \mathrm{~cm}$ spacing. After curing for 28 days, the hinge joint test was performed. The final test girder is shown in Figure 4. The IDs for the hollow slab and hinge joint are shown in Figure 5.

\section{Test Loading and Measurement Point Deployment}

3.1. Test Loading. The main subject of this experimental study was the hollow slab hinge joint structure. Based on Section 4.3.1(2) in the General Code for Design of Highway Bridges and Culverts (JTG D60-2004), the local load calculation of the bridge structure was based on vehicle load [14]. Based on the principle of the most unfavorable deployment, standard vehicle rear axial load was converted to uniformly distributed stress on the test girder. Additionally, the load of two wheels was applied to the same horizontal position. The ground contact area of standard vehicle rear axle tire was $0.6 \mathrm{~m} \times 0.2 \mathrm{~m}$ [14]. The detailed loading position is shown in Figure 6.

In the test, a hydraulic jack was used for simultaneous loading at two points. The relationship between the load and the designed vehicle load is listed in Table 1 . Before the test, the hollow slab girder was preloaded to $140 \mathrm{kN}$ to confirm whether all measurement points were in a normal operational state. Then, the load was reduced to $0 \mathrm{kN}$ and reapplied for each grade.

\subsection{Placement of the Measurement Point for the Hollow} Slab Girder. To understand the hinge joint load transmission effect, the hollow slab deflection measurement point placement is shown in Figure 7. In the direction vertical to the bridge, they are placed at 3 sections, i.e., the L/4 section, 


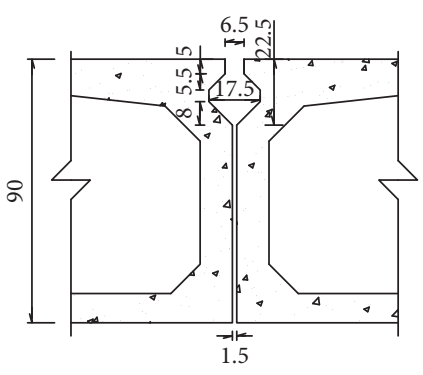

(a)

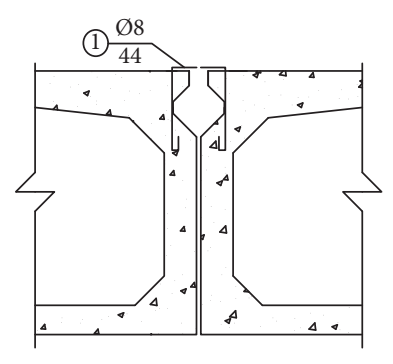

(b)

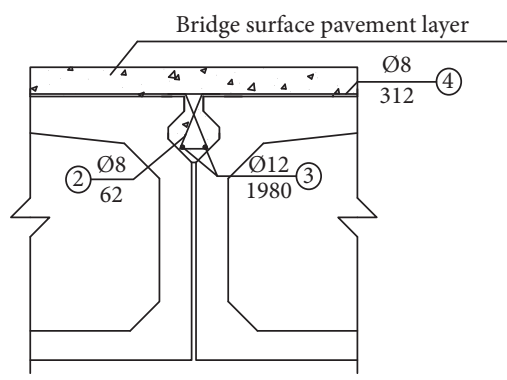

(c)

FIgURe 2: Hinge joint structure and reinforcement (cm): (a) hinge joint detailed drawing, (b) hinge joint connection rebar, and (c) hinge joint rebar.

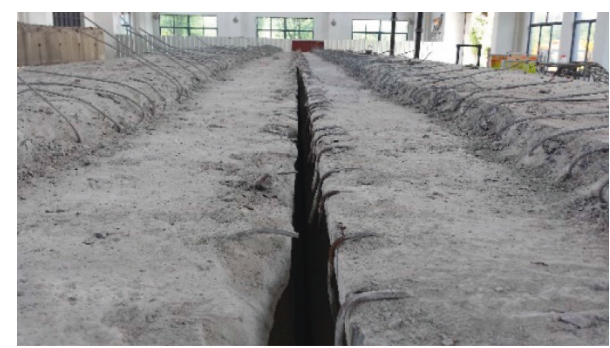

Figure 3: Hollow slab girder.

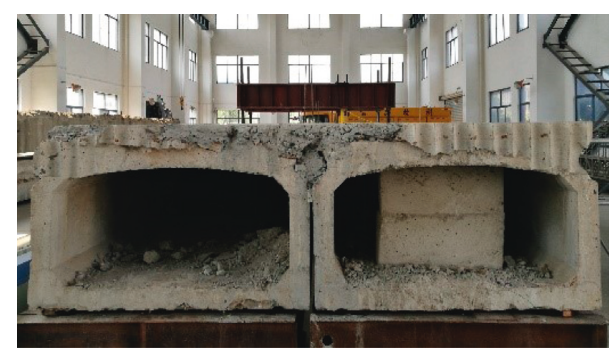

Figure 4: Hollow slab prototype test.

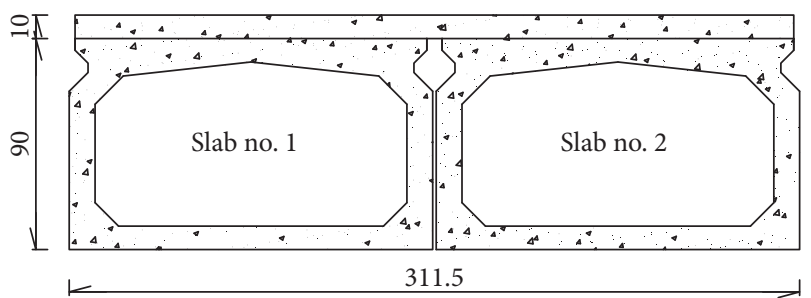

FIgURE 5: Cross section of a hollow slab (cm).

the $\mathrm{L} / 2$ section, and the $3 \mathrm{~L} / 4$ section. The IDs of the deflection measurement points at slab no. 1 are D1-1, D1-2, and D1-3. The IDs of the deflection measurement points at slab no. 2 are D2-1, D2-2, and D2-3.

The hollow slab strain gauge measurement points are placed at the $\mathrm{L} / 4$ section, the $\mathrm{L} / 2$ section, and the $3 \mathrm{~L} / 4$ section along the direction vertical to the bridge, as shown in Figure 8. The IDs of the strain measurement points for hollow slab no. 1 are S1-1, S1-2, S1-3, and S1-4 (midspan roof). The IDs of the strain measurement points for hollow slab no. 2 are S2-1, S2-2, S2-3, and S2-4 (midspan roof).

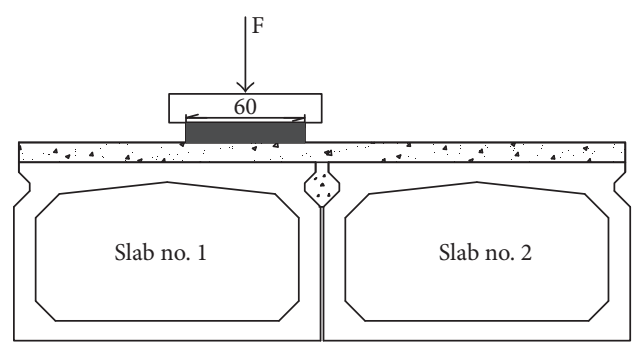

(a)

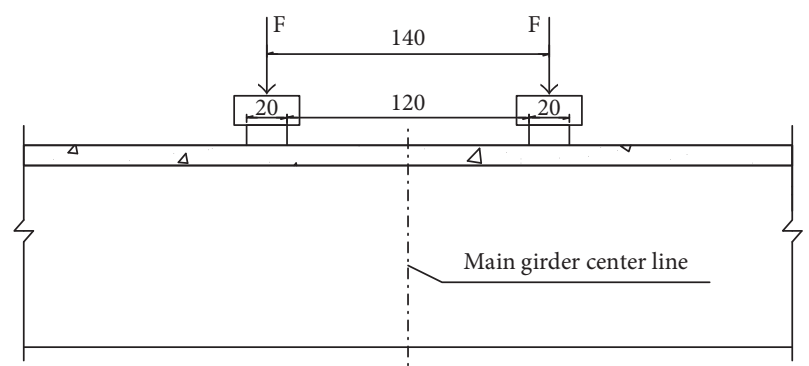

(b)

FIGURE 6: Vehicle loading position: (a) direction horizontal to the bridge and (b) direction vertical to the bridge.

TABLE 1: Load and corresponding designed vehicle load.

\begin{tabular}{lc}
\hline Load $(\mathrm{kN})$ & Vehicle load (highway-grade I)(times) \\
\hline 70 & 0.25 \\
140 & 0.50 \\
210 & 0.75 \\
280 & 1.00 \\
350 & 1.25 \\
420 & 1.50 \\
490 & 1.75 \\
560 & 2.00 \\
\hline
\end{tabular}

3.3. Deployment of Measurement Points at the Hinge Joint. The relative displacement difference is an important index to evaluate the hinge joint damage level and load-transfer performance. In this test, 4 measurement points were used to measure the change of the hinge joint relative position. Among them, JD1-1 and JD1-2 measured the vertical displacement of the hinge joint; JD2-1 and JD2-2 measured the horizontal displacement of the hinge joint. They 


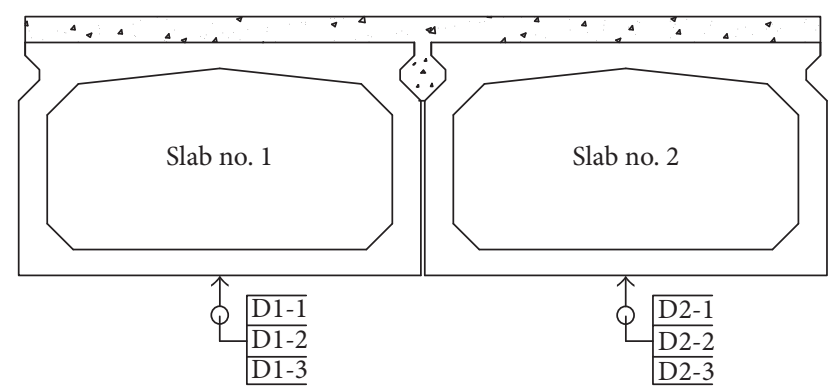

个 Gauge

Figure 7: Deflection measurement points for the hollow slab.

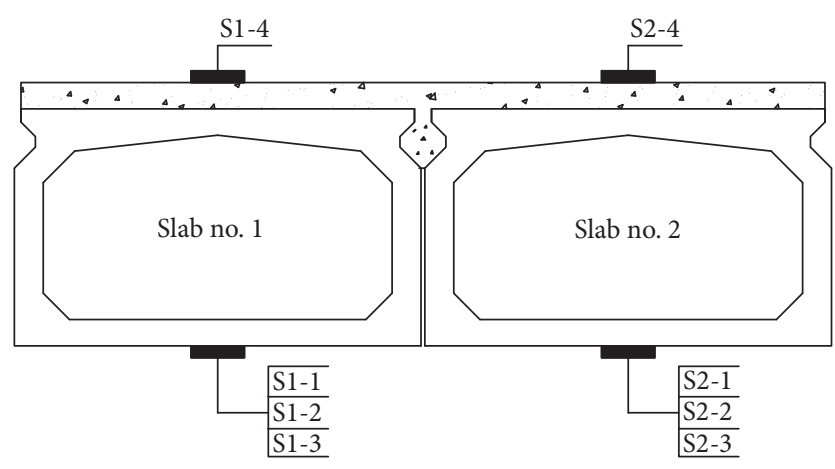

Strain meter

FIgURE 8: Strain measurement points for the hollow slab.

are placed at the midspan section along the direction vertical to the bridge, as shown in Figure 9.

Before pouring concrete at the hinge joint, measurement points for the hinge joint $x$ direction strain are buried at the midspan in advance along the direction vertical to the bridge. The IDs of the strain measurement points along the hinge joint height direction are JS1, JS2, JS3, JS4, and JS5. Detailed placement is shown in Figure 10.

\section{Test Results and Analysis}

4.1. Test Procedure. For each loading stage in the test, the load-deflection curve and load-strain curve of the hollow slab are shown in Figures 11 and 12.

At the initial stage of loading, the structure stress was in the elastic stage. The load-deflection curves of two slabs demonstrated a linear variation. Additionally, the variation rates were consistent. The bonding surface between the hinge joint and girder had no fracture.

When the load increases to approximately $365 \mathrm{kN}$, i.e., 1.3 times the designed vehicle load (highway-grade I), the midspan pure bending sections of hollow slabs no. 1 and no. 2 developed bending fractures. The structures entered the elastoplastic state. The stiffness reduced gradually. When the load increased further, the slab load-deflection curves demonstrated a nonlinear variation. This stage continued until the load reached $560 \mathrm{kN}$, i.e., 2.0 times the designed vehicle load (highway-grade I). At this moment, the roof concrete of hollow slabs no. 1 and no. 2 approached collapse.

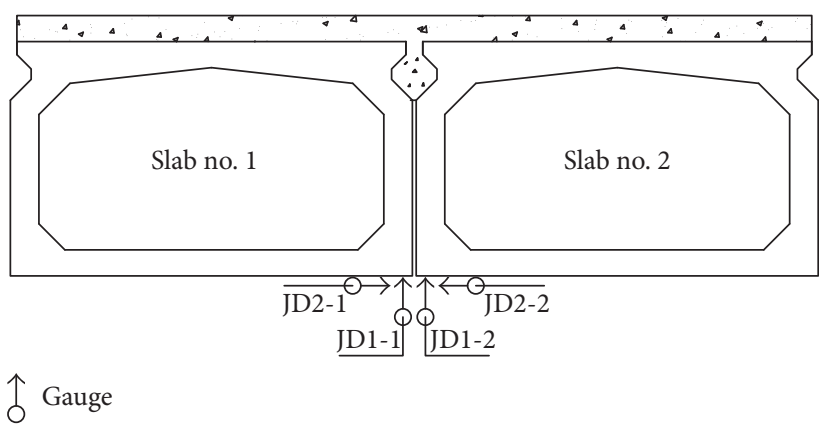

Figure 9: Displacement measurement points at the hinge joint.

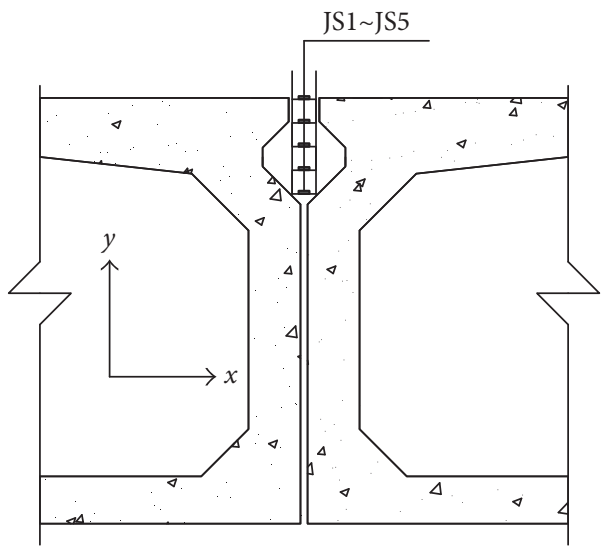

FIgURE 10: Strain measurement points at the hinge joint.

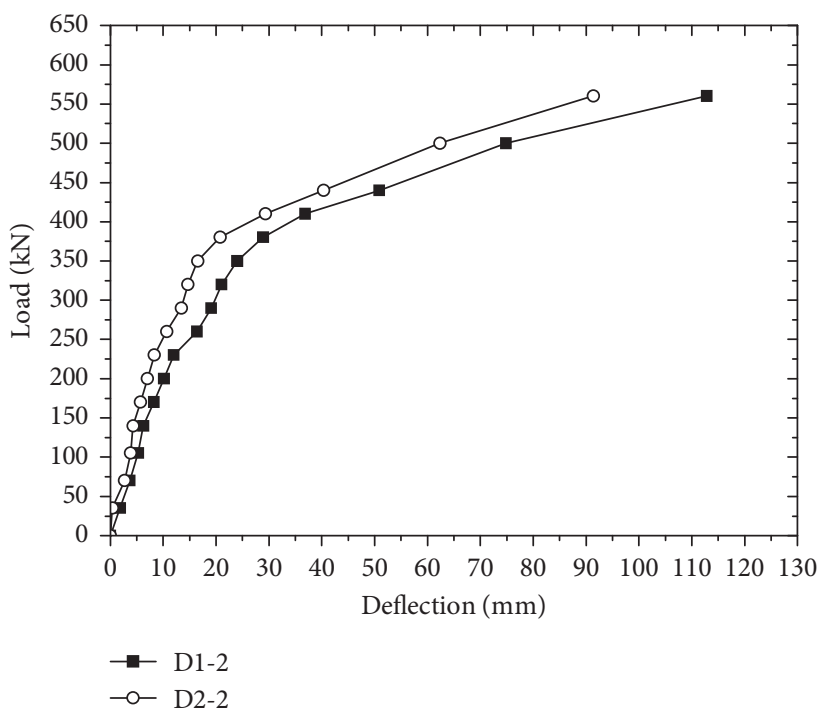

FIgURE 11: Load-deflection curve at the midspan section of the hollow slab.

During the entire testing process, fracture at the hollow slab grew continuously. When the load reached $560 \mathrm{kN}$, midspan bending fracture reached the maximum width of $5 \mathrm{~mm}$; however, the bonding surface between the hinge joint and the hollow slab girder showed no fracture during the entire testing process. 


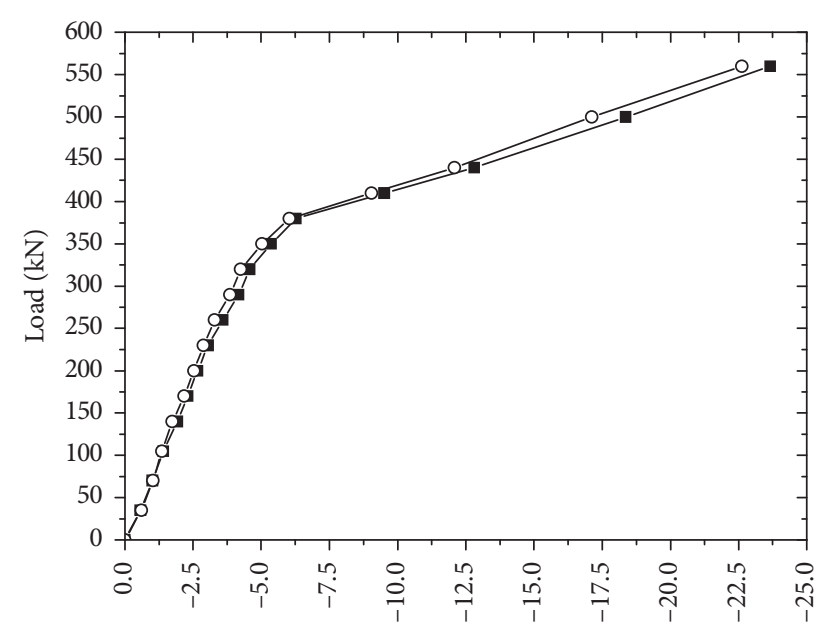

Stress $(\mathrm{MPa})$

$$
\begin{aligned}
& -\square-S 1-4 \\
& -0-S 2-4
\end{aligned}
$$

FIGURE 12: Load-stress curve at the midspan roof of the hollow slab.

4.2. Relative Hinge Joint Displacement. Variations of hinge joint horizontal opening and vertical relative displacement at the L/2 section compared to load are shown in Figures 13 and 14. The diagrams show that during the entire loading process, hinge joint horizontal opening and vertical relative displacement essentially increased linearly with load. When the load reached $560 \mathrm{kN}$, the horizontal opening was $0.153 \mathrm{~mm}$ and the vertical relative displacement was $0.201 \mathrm{~mm}$. When the test loading was completed, hinge joint fracture was not observed.

4.3. Stress on Hinge Joint. Traverse stresses at strain measurement points JS1 JS5 at the midspan along the height direction of the hinge joint section are shown in Figure 15. During the entire loading process, the bottom of the hinge joint was under tension (JS1 JS4 measurement points), and the top was under compression (JS5 measurement point). As the load increased, stress at the measurement point basically changed linearly. When the load reached $560 \mathrm{kN}$, tensile stress at measurement point JS1 at the bottom of the hinge joint was $0.56 \mathrm{MPa}$.

\section{Hinge Joint Shear Capacity Calculation}

Currently, codes in China have not specified how to calculate the shear capacity of hinge joints. Normally, the shear capacity of a hinge joint is calculated via the formula for the shear capacity of a concrete bonding surface. Next, calculation formulae in North America and bridge masonry specifications in China are elaborated.

(1) The shear capacity calculation formula in concrete structure design specifications in the United States (ACI 31805) $[15,16]$ is as follows:

$$
V_{\mathrm{n}}=A_{\mathrm{vf}} f_{\mathrm{y}} \mu,
$$

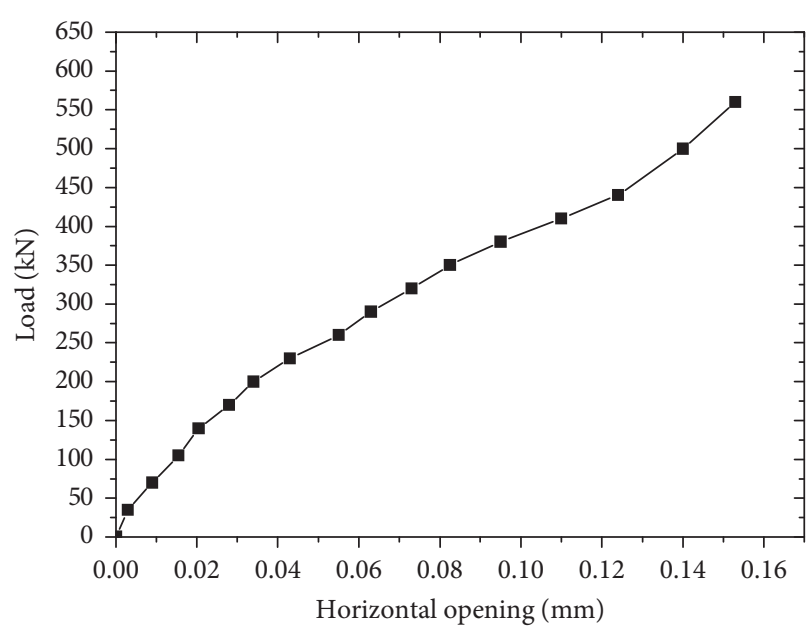

FIgURE 13: Load-horizontal opening curve at the hinge joint.

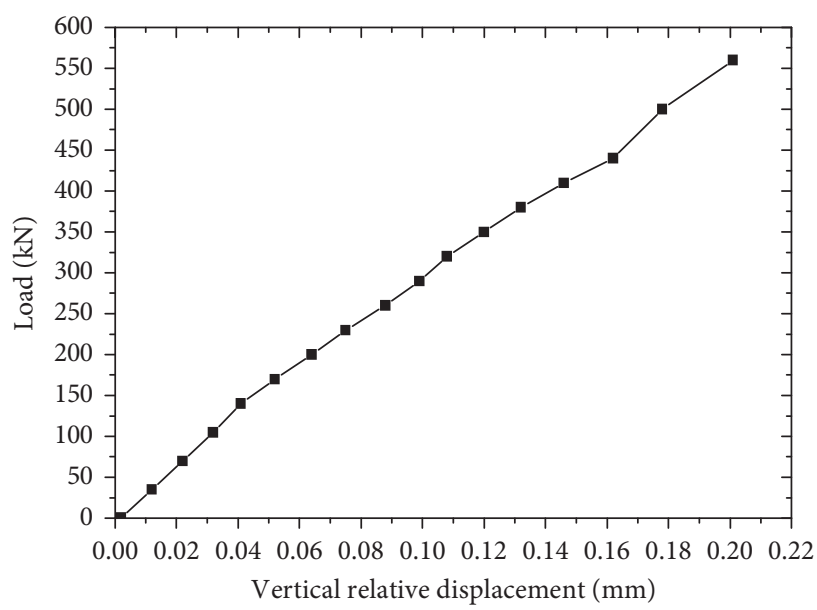

FIGURE 14: Load-vertical relative displacement curve at the hinge joint.

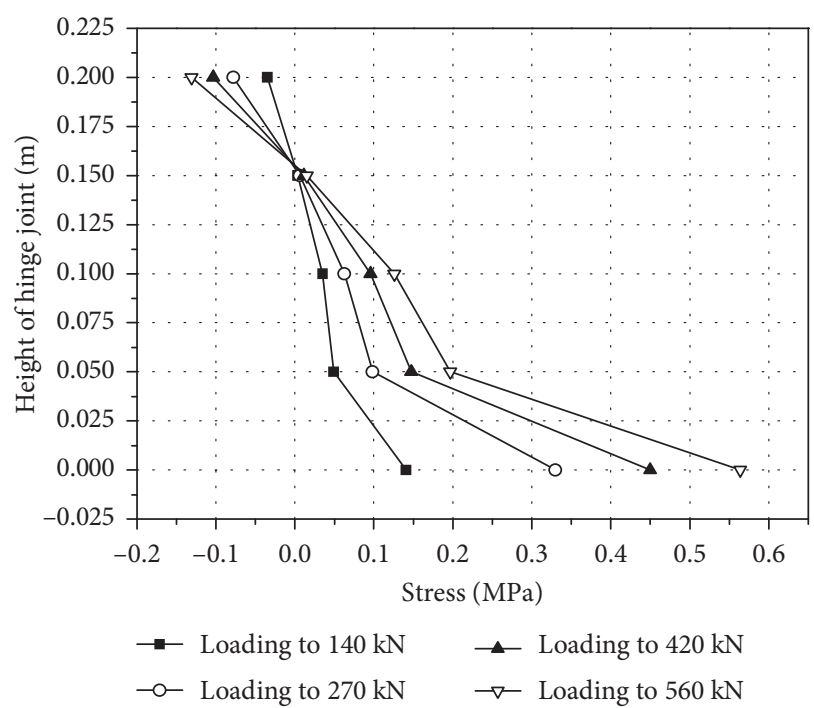

FIgURE 15: Transverse strain curves along the section height of the hinge joint. 
where $V_{\mathrm{n}}$ is the shear capacity of the bonding surface; $A_{\mathrm{vf}}$ is the area of friction shear rebar; $f_{\mathrm{y}}$ is the yield strength of shear rebar; and $\mu$ is the friction coefficient, whose value is determined as follows:

When concrete is poured as a whole, $\mu=1.4 \lambda$; when concrete is poured on the surface of existing hardened concrete that undergoes a roughening process, $\mu=1.0 \lambda$; when concrete is poured on the surface of existing hardened concrete without roughening, $\mu=0.6 \lambda$; and when concrete is fixed to the section steel via rebar, $\mu=0.7 \lambda$,

The value of $\lambda$ is determined as follows:

When ordinary concrete is used, $\lambda=1.0$; when lightweight sand concrete is used, $\lambda=0.85$; and when lightweight concrete is used, $\lambda=0.75$.

(2) Canadian highway bridge design code [17]

In Canadian highway bridge design code, the calculation formula for the shear strength of the bonding surface is as follows:

$$
v=\phi_{c}(c+\mu \sigma)
$$

where $v$ is the shear strength of the bonding surface, which does not exceed $0.25 \phi_{\mathrm{c}} f_{\mathrm{c}}^{\prime}$ or $6.5 \mathrm{MPa} ; \phi_{c}$ is the concrete reduction coefficient; and $f_{c}^{\prime}$ is the specified compressive strength of concrete.

In (2), the values of $c$ and $\mu$ are determined as follows:

When concrete is poured on the surface of existing hardened concrete without roughening, $c=0.25 \mathrm{MPa}, \mu=0.60 \lambda_{1}$; when concrete is poured on the surface of existing hardened concrete that undergoes a roughening process, $c=0.50 \mathrm{MPa}, \mu=1.00 \lambda_{1}$; and when concrete is poured as a whole, $c=1.00 \mathrm{MPa}$, $\mu=1.40 \lambda_{1}$.

When the material is ordinary concrete, $\lambda_{1}=1.0$; when it is lightweight sand concrete, $\lambda_{1}=0.85$; and when it is lightweight concrete, $\lambda_{1}=0.75$.

In (2), $\sigma$ is calculated as follows:

$$
\sigma=\rho_{\mathrm{v}} f_{\mathrm{y}}+\frac{N}{A_{\mathrm{cv}}}
$$

where $f_{\mathrm{y}}$ is the yield strength of shear rebar; $\rho_{\mathrm{v}}$ is the reinforcement ratio of shear section, $\rho_{\mathrm{v}}=A_{\mathrm{vf}} / A_{\mathrm{cv}} ; N$ is the lateral pressure on shear section; $A_{\mathrm{vf}}$ is the area of shear rebar; and $A_{\mathrm{cv}}$ is the section area of shear concrete.

(3) Chinese code for the design of highway masonry bridges and culverts (JTG D61-2005) [18]

According to section 4.0.13 in the Code for Design of Highway Masonry Bridges and Culverts, when the normal section of the structure is directly under shear stress, the calculation formula is as follows:

$$
\gamma_{0} V_{\mathrm{d}} \leq A f_{\mathrm{vd}}+\frac{1}{1.4} \mu_{\mathrm{f}} N_{\mathrm{k}}
$$

where $V_{\mathrm{d}}$ is the designed shear stress at hinge joint; $\gamma_{0}$ is the significance coefficient of structure; $A$ is the area of shear section; $f_{\mathrm{vd}}$ is the designed concrete shear strength, whose value is listed in Table $2 ; \mu_{\mathrm{f}}$ is the friction coefficient, $\mu_{\mathrm{f}}=0.7$; and $N_{\mathrm{k}}$ is the standard pressure vertical to the shear section.

The shallow hinge joint in this test is used as an example to calculate the shear capacity and shear strength of the
TABLE 2: Designed concrete shear strength.

\begin{tabular}{lllllll}
\hline Strength grade & C40 & C35 & C30 & C25 & C20 & C15 \\
\hline$f_{\text {vd }}$ & 2.48 & 2.28 & 2.09 & 1.85 & 1.59 & 1.32 \\
\hline
\end{tabular}

\begin{tabular}{|c|c|c|}
\hline Standard & $\begin{array}{l}\text { Shear capacity, } \\
\text { strength }\end{array}$ & $\begin{array}{c}2.0 \text { times the designed } \\
\text { hinge } \\
\text { joint shear (stress) under } \\
\text { vehicle load }\end{array}$ \\
\hline $\begin{array}{l}\text { United States: } \\
\text { ACI } 318-5\end{array}$ & $V_{\mathrm{n}}=88.4 \mathrm{kN}$ & $V_{\mathrm{d}}=72.3 \mathrm{kN}$ \\
\hline $\begin{array}{l}\text { Canada: } \\
\text { CAN/CSA-S6-00 }\end{array}$ & $v=0.52 \mathrm{MPa}$ & $v_{\mathrm{d}}=0.32 \mathrm{MPa}$ \\
\hline China: JTG D61-2005 & $A f_{\mathrm{vd}}=558 \mathrm{kN}$ & $V_{\mathrm{d}}=72.3 \mathrm{kN}$ \\
\hline
\end{tabular}

TABLE 3: Calculation of the shear bearing capacity and the strength of shallow hinge joints.

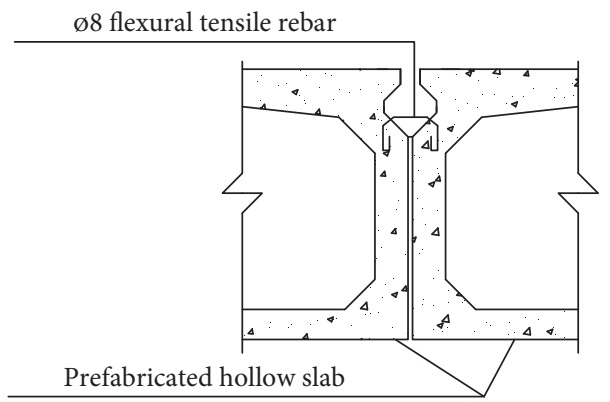

Figure 16: Tensile rebar of the hinge joint.

hinge joint based on the aforementioned three specifications. Based on hinge slab theory, the shear force and shear stress of the hinge joint under 2.0 times the designed vehicle load are calculated (for detailed procedure, please refer to [19]). The above calculation results are listed in Table 3.

Table 3 shows that the shear capacity and shear strength of the hinge joint calculated from the three specifications exceed the calculated shear stress of the hinge joint under 2.0 times the vehicle load (highway-grade I). Among them, the calculation results from the specifications in the United States and Canada are similar; the shear capacity calculated from the Chinese specification significantly exceeds the designed shear value of the hinge joint because in Chinese specifications, the designed direct concrete shear strength $f_{\mathrm{vd}}$ is based on Table 2, while the actual shear failure of hinge joint concrete is determined by the shear strength of new-old concrete bonding surface between the hinge joint and girder.

\section{Conclusions}

(1) Two prestressed concrete hollow slabs with a $20 \mathrm{~m}$ span (with shallow hinge joint structure) were used as test subjects to conduct an experimental study on shallow hinge joints under vehicle load. Under eccentric load, the shallow hinge joint was primarily under shear stress; tensile stress at the bottom was small. The test results and observations of traverse 


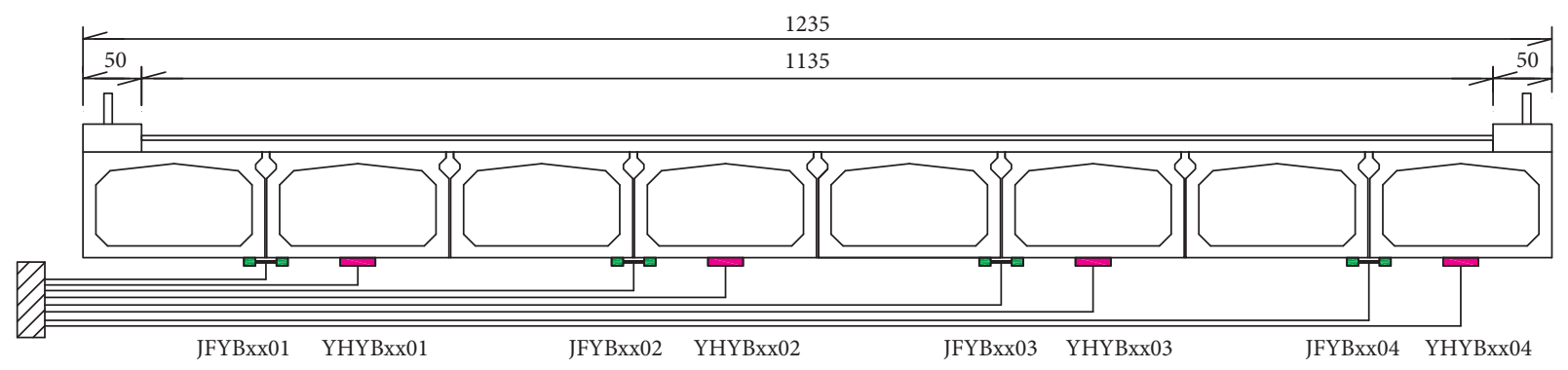

Figure 17: Layout of strain measurement points.

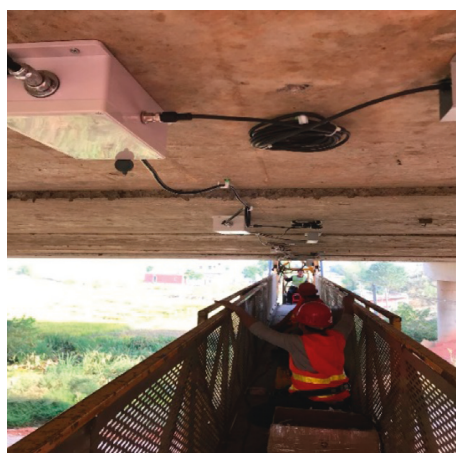

(a)

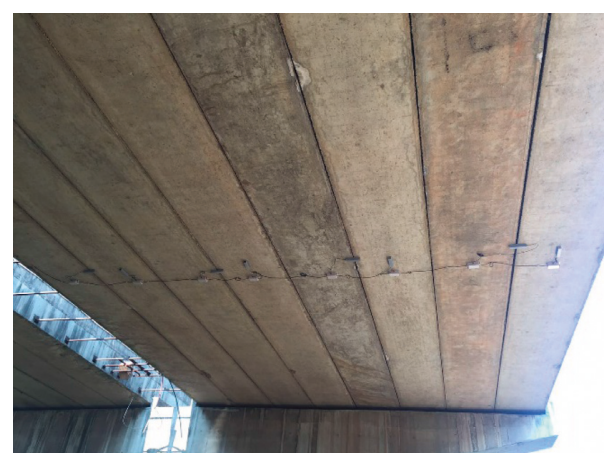

(b)

FIgURE 18: Site installation of strain measurement points.

stress, horizontal opening, and vertical relative displacement of the hinge joint showed no sign of fracture when the load reached 2.0 times the designed vehicle load (highway-grade I).

(2) Theoretical calculation results from the ACI 318-5 specification in the United States, Canadian CAN/CSA-S6-00, and Chinese specification JTG D61-2005 show that the shallow hinge joint structure possesses desirable shear capacity. Compared with Chinese specification JTG D61-2005, the two specifications in North America consider factors such as coarseness of bonding surface, concrete pouring sequence, and material properties. Therefore, they are more suitable for hinge joint shear capacity calculations.

(3) The test and theoretical calculation results show that under 2.0 times the highway-grade I eccentric load, the hinge joint structure did not develop shear failure. In an actual project, a shallow hinge joint is under complex stress, including bending, stretching, and shearing; the hinge joint will likely fracture, and "stress on a single slab" will likely occur. These phenomena are mainly caused by insufficient bending and tensile strength of the bonding surface between the hinge joint and the hollow slab. In this test, the hinge joint was primarily under shear stress; the flexural tensile stress on the bonding surface was small. Therefore, the shallow hinge joint showed no failures. This finding indirectly proves that hinge joint fracture is controlled by flexural tensile stress on the bonding surface. It is suggested that the tensile bearing capability of the bonding surface between the hinge joint and the hollow slab should be enhanced by some structures and reinforcement measures, as shown in Figure 16.

(4) Through the experimental study of this paper, the shear resistance of the shallow hinge joint was clearly revealed. According to the test results, it can provide reference for the reinforcement design and maintenance of shallow hinge joint.

In order to verify the conclusion of test and monitor the health of hollow slab in the long term, a number of test points for the lateral strain of the hinge joint and the longitudinal strain across the middle of the hollow slab have been arranged on the real bridge recently, as shown in Figures 17 and 18. It was found that there was no disease phenomenon in the hinge joint based on the most recent monitoring data.

\section{Data Availability}

All the data in the article are the measured values of the test and are included within the article or available from the corresponding author upon request.

\section{Conflicts of Interest}

The authors declare that they have no conflicts of interest. 


\section{Acknowledgments}

The study was supported by the National Natural Science Foundation Youth Science Foundation Project (Project no. 51408009).

\section{References}

[1] J. Yunxia, C. Jinyi, W. Biqing et al., "Study on hinge slab bridge reinforcement without interrupting traffic," Journal of Inner Mongolia Highway and Transport, no. 2, pp. 1-3, 2002.

[2] C. Yuechi, W. Qingxiong, and C. Baochun, "Failure mode of hinge joint in assembly voided slab bridge by finite element analysis," Journal of Engineering Mechanics, vol. 31, no. S1, pp. 51-58, 2014.

[3] Y. Jixin, "Study on stress performance of hinge joint in prefabricated hollow slab bridge," Inner Mongolia University of Technology, Huhhot, Mongolia, 2009.

[4] Y. Jianshu, L. Jiusheng, Y. Bo et al., "Experimental study on shear performance of hinge joint of concrete hollow slab," Journal of Highway and Transportation Research and Development, vol. 30, no. 6, pp. 33-39, 2013.

[5] C. Yongfeng, Experimental Study on Hollow Slab Girder Hinge Joint Model, Chang'an University, Xi'an, China, 2008.

[6] W. Tiecheng, X. Hui, and L. Shaowei, "Experimental study on bridge slab structure optimization," Journal of Central South Highway Engineering, vol. 31, no. 3, pp. 45-48, 2006.

[7] T. Xianxi, Y. Yueyou, G. Wei et al., "Experimental study on fatigue performance of hinge joint of hinged slab bridge," Journal of Water Resources and Architectural Engineering, vol. 13, no. 1, pp. 6-10, 2015.

[8] W. Qu, W. Qingxiong, and C. Baochun, "Experimental study on failure mode of hinge joint of prefabricated hollow slab," Mechanics Engineering, vol. 31, pp. 115-120, 2014.

[9] Chinese Technical Specification, JTG D60-2004 General Code for Design of Highway Bridges and Culverts, China Communications Press, Beijing, China, 2004.

[10] K. E. Hanna, G. Morcous, and M. K. Tadros, "Transverse posttensioning design and detailing of precast, prestressed concrete adjacent box-girder bridges," PCI Journal, vol. 54, no. 4, pp. 160-174, 2009.

[11] G. Annamalai and R. C. Brown, "Shear strength of posttensioned grouted keyed connections," PCI Journal, vol. 35, no. 3, pp. 64-73, 1990.

[12] G. Annamalai and R. C. Brown, "Shear transfer behavior of post-tensioned grouted shear key connections in precast concrete-framed structures," ACI Structural Journal, vol. 87, no. 1 , pp. 53-60, 1990.

[13] A. A. Huckelbridge, F. Moses, and H. E. Esnawi, "Shear key performance in multi-beam box girder bridges," Journal of Performance of Constructed Facilities, vol. 9, no. 4, pp. 271285, 1995.

[14] R. A. Miller, G. M. Hlavacs, and T. Long, "Full-scale testing of shear keys for adjacent box girder bridges," PCI Journal, vol. 44, no. 6, pp. 80-90, 1999.

[15] AASHTO, Standard Specifications for Highway Bridges, American Association of State Highway and Transportation Officials, Washington, DC, USA, 17th edition, 2002.

[16] AASHTO, LRFD Bridge Design Specifications, American Association of State Highway and Transportation Officials, Washington, DC, USA, 4th edition, 2007.

[17] Standards Council of Canada, CAN/CSA-S6-00 Canadian Highway Bridge Design Code, CSA International, Etobicoke, ON, Canada, 2000.
[18] Ministry of Transport of China, JTG D61-2005 Code for Design of Highway Masonry Bridges and Culverts, China Communications Press, Beijing, China, 2005.

[19] B. Bakht and L. G. Jaeger, Bridge Analysis Simplified, McGrawHill Press, New York, NY, USA, 1985. 


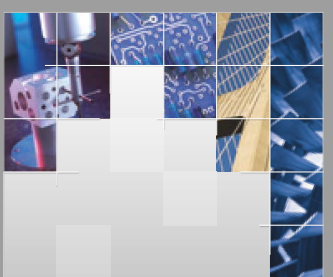

\section{Enfincering}
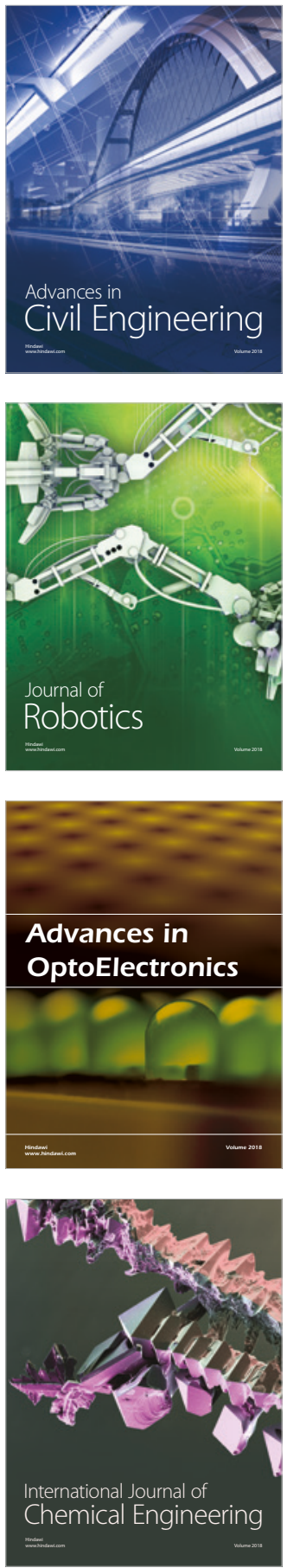

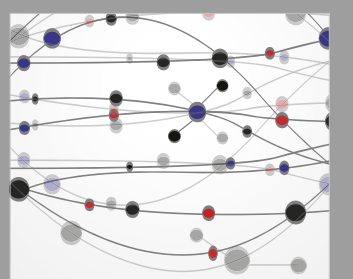

\section{Rotating \\ Machinery}

The Scientific World Journal

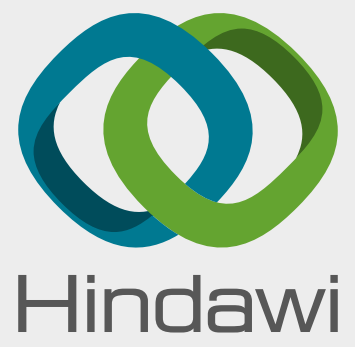

Submit your manuscripts at

www.hindawi.com
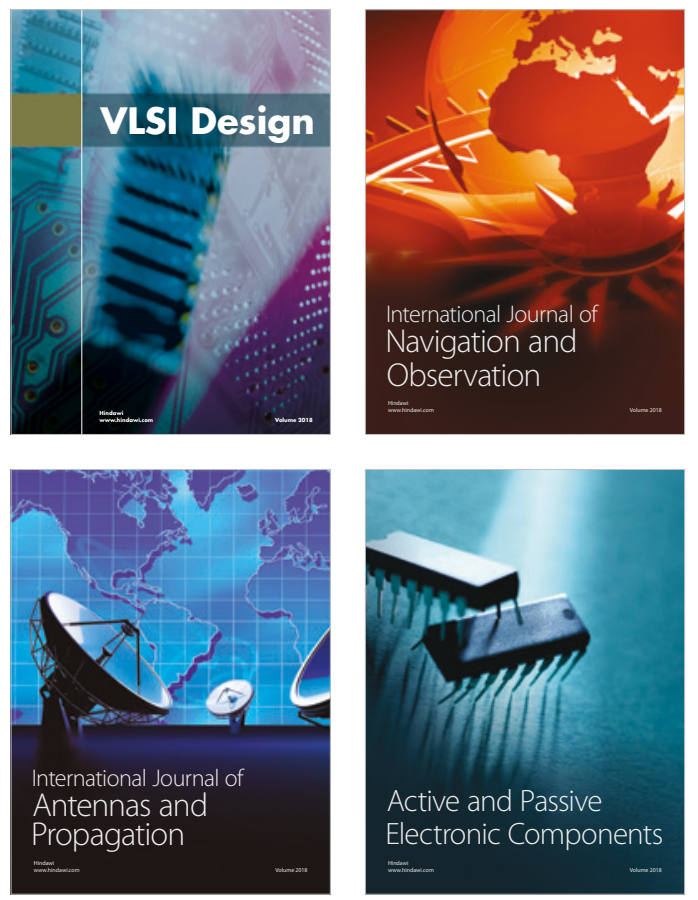
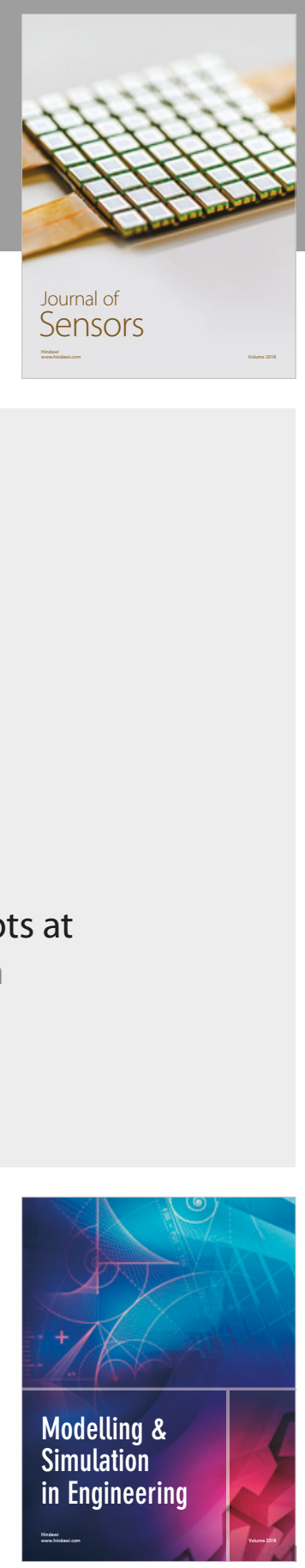

\section{Advances \\ Multimedia}
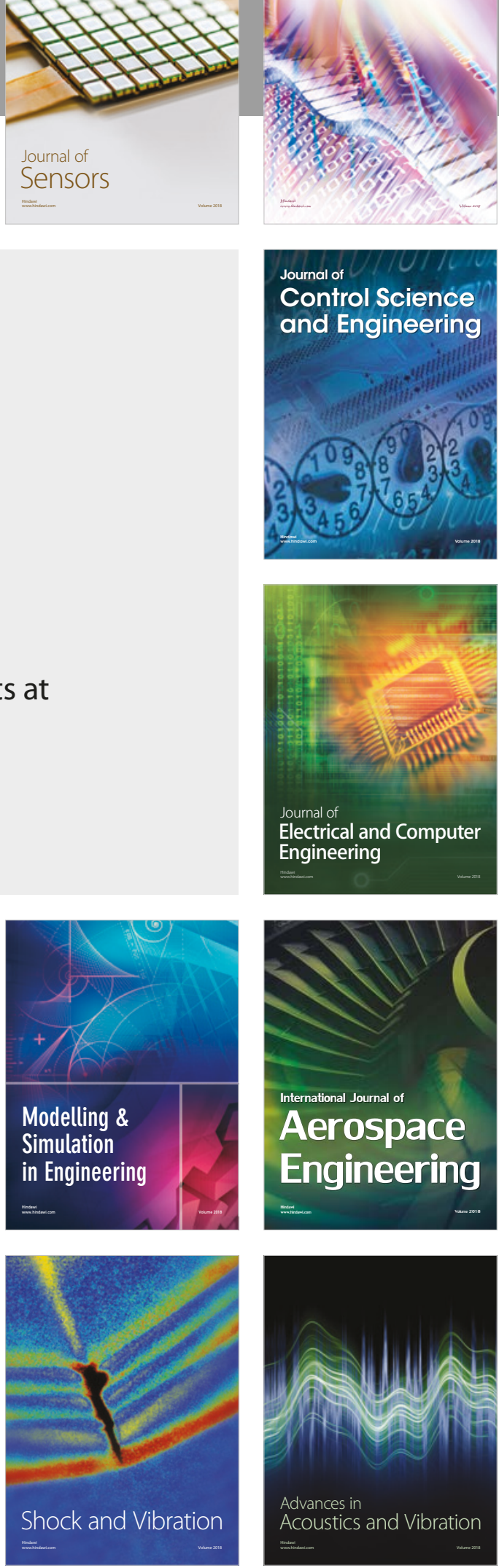